\title{
BISPHOSPHONATE - RELATED OSTEONECROSIS OF THE JAW - FIVE YEARS EXPERIENCE
}

\author{
Stilla $\mathrm{J}^{1}$, Statelova $\mathrm{D}^{1}$, Janickova $\mathrm{M}^{1}$, Malachovsky $\mathrm{I}^{1}$, Gengelova $\mathrm{P}^{1}$, Jurkemik $\mathrm{J}^{1}$, \\ Adamicova $\mathrm{K}^{2}$
}

${ }^{1}$ Department of Stomatology and Maxillofacial Surgery, Jessenius Medical Faculty of Commenius University; University Hospital in Martin

${ }^{2}$ Department of Pathological Anatomy, Jessenius Medical Faculty of Commenius University; University Hospital in Martin

\section{A bs tract}

Background. Osteonecrosis related to bisphosphonate therapy is a challenging disease with complicated treatment. It is well known among the maxillofacial surgeons all around the world since 2003. Despite of it, the incidence is still rising, because of the lack of prevention before using bisphosphonates. Disturbing the bone metabolism leads by even a small trauma to enormous defects, that is despite of intensive therapy irreversible. Treatment of this disease is commonly joint with losing the bone tissue and badly affects the quality of life. Often is necessary the combined therapy, surgery, antibiotics and antimycotics. The discontinuation of bisphosphonate treatment during the osteonecrosis therapy is also recommended if it is possible.

Methods and results. We examined and treated 79 patients with bisphosphonate related osteonecrosis of the jaw. The comparison of several methods of treatment was made in all stages of disease, with research of the therapy length, complications together with the need of reoperation and following up all the patients during five years. The results of the therapy were in most cases satisfactory; only two patients had problems that persisted. None of the patients died because of this disease.

Conclusions. Bisphosphonate related osteonecrosis of the jaw is a disease that is difficult to treat. For patient it costs too much, not because of using the expensive antibiotics, but mostly because it leads to the defects in patient's jaw, it is affecting the oral intake and the life of the patient at all. Prevention is the best way to discontinuation of the rising incidence, but it requires a cooperation of interested specialists and also perfect education of the patient.

Keywords: bisphosphonate, osteonecrosis, jaw, therapy

\section{INTRODUCTION}

Bisphosphonate - related osteonecrosis of the jaw (BRONJ) is a common and actual problem in maxillofacial surgery. Despite of many publications on this topic, there are still unanswered questions in pathogenesis, but also what therapy is best and most efficient. First bisphosphonate (BP) etidronate was registered in USA in 1977 and was used for Paget's disease treatment. Afterwards were BPs used for various bone diseases (1). First BPs were administered orally and the number of diseases that could be treated with BPs was rising continuously .First bisphosphonates were not aminated. In 1994 was for the first time registered in USA nitrogen containing BP and afterwards its usage was extended for other diseases including osteoporosis, osteopenia, paraneoplastic hypercalciaemia and skeletal manifestations of malignant tumors, whether primary (multiple myeloma), or skeletal metastases of cancers (1). Using of the non-aminated BPs was not discontinued, but nowadays it's less used. BP can be administered perorally or intravenously. Oral forms are mostly prescribed by rheumatologists and internists for treatment of the osteoporosis. Hematologists and oncologists are mostly using intravenous nitrogen containing BP. Treatment with BP has not a major effect on survival of the patients but it has significantly positive effect on the quality of life in advanced stage oncologic patients with skeletal conditions (2).

Address for correspondence:

MUDr. Juraj Štilla; Kollarova Str.N.2, 03601 Marti, Slovak Republic

Phone: +421 434203 517; e-mail: jstilla@gmail.com 
Using of BP has advantage in algorithm of administration, with its monthly or yearly interval. It has also only small number of side effects, when it is correctly used. One of the most serious side effect of BP therapy is osteonecrosis of the jaw. Maxillofacial surgeons were first to describe cases of non-healing gingival and bone defects in jaws of patients treated with bisphosphonates $(3,4)$. After the year 2003 it is becoming more and more common and nowadays there isn't probably any maxillofacial surgeon which has not been met by this disease. For osteonecrosis of maxilla and mandible caused by bisphosphonates is in literature most common name given by American Association of Oral and Maxillofacial Surgery (AAOMS) - Bisphosphonate - related osteonecrosis of the jaw (BRONJ; 5)

Diagnosis of BRONJ is not very difficult. Constant symptoms are persisting ulcers of the oral mucosa, disclosing the jaw bone (Fig.1), pain and changes in X-ray (Figure 2), CT or MRI, together with the history of previous or current use of the bisphosphonate. AAOMS uses three required conditions for BRONJ diagnosis (5). Patient has to be previously or currently using BP, the bone should be exposed at least 8 weeks and patient didn't undergo radiotherapy of head and neck.

The risk factors are defined by AAOMS in the position paper (2). It is steroid intake, smoking, the intake of cytostatic drugs, and poor oral hygiene.

Until nowadays remain unanswered many questions in pathophysiology of this disease and why it is so common in jaws and not in the other bones. Suppression of the bone remodelation induced by $\mathrm{BP}$ is the most likely mechanism of this disease $(6,7)$. Fast and continuous remodelation of jaws, caused by the presence of the teeth may be the reason of its vulnerability to BP (8). One study has shown ongoing changes in remodelation of the cortical jaw bone after BP use. Daily administered alendronate significantly lowered speed mandible bone formation compared to a control group, mainly because of suppression of

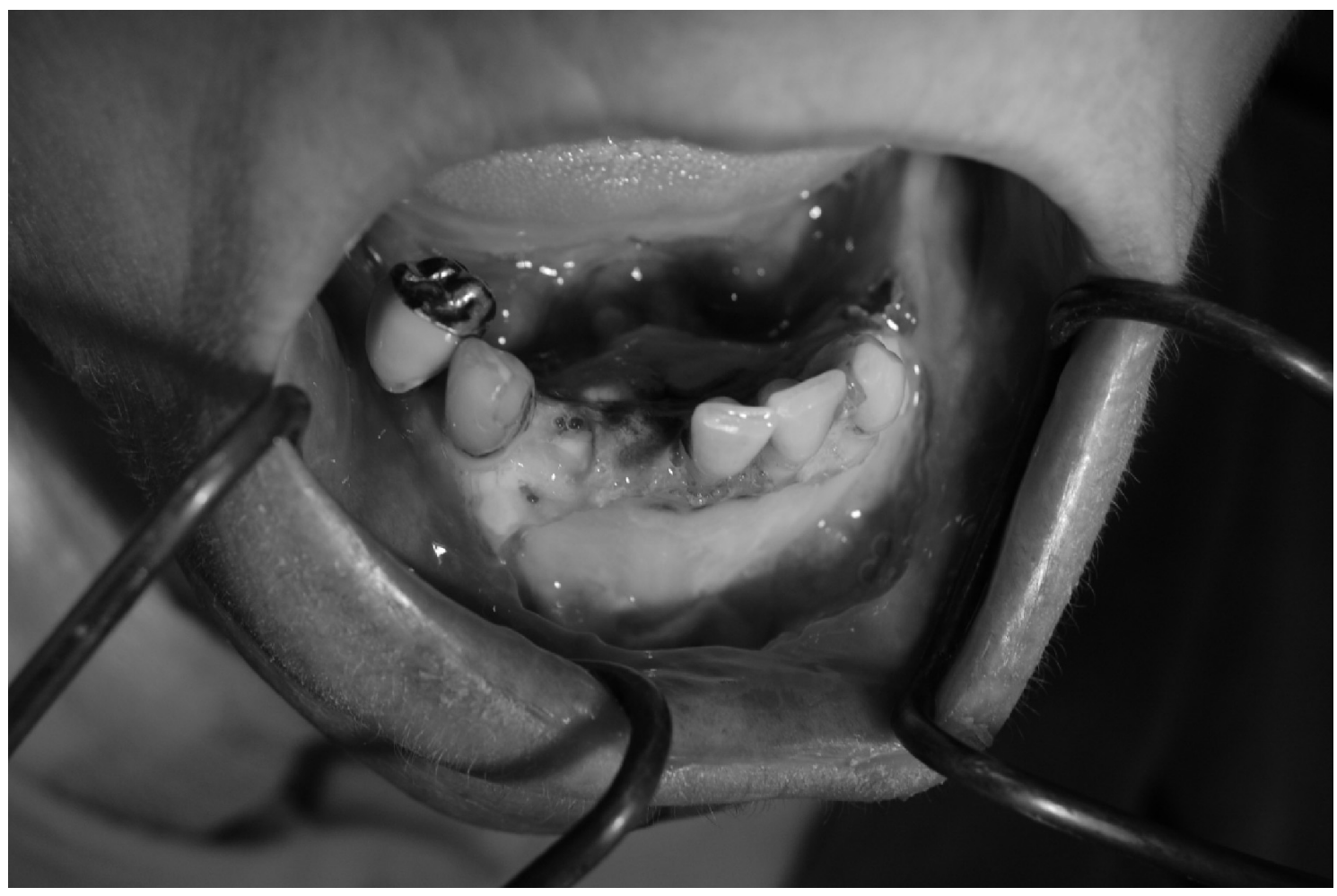

Fig. 1 Dehiscence of the oral mucosa in the frontal area of mandible 


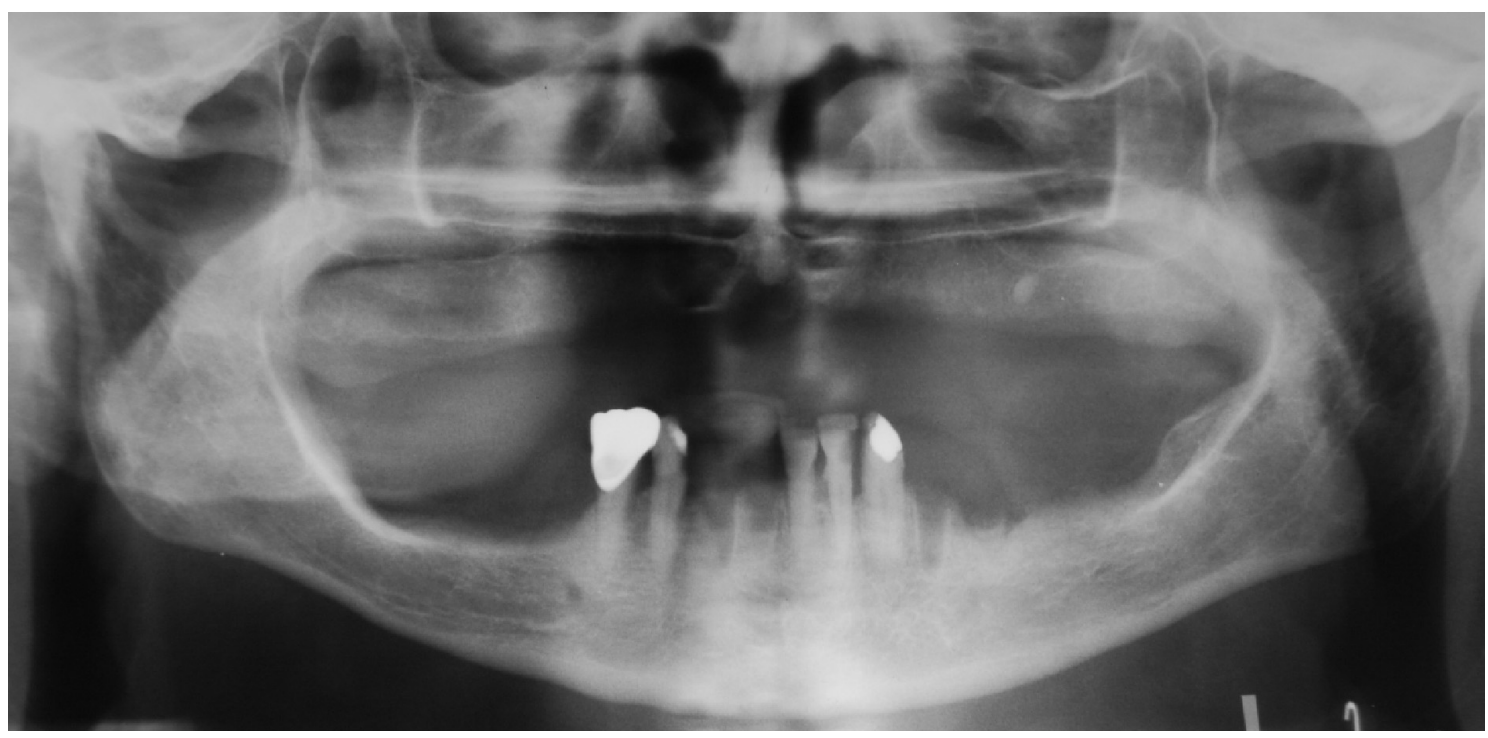

Fig. 2 The orthopantomographic $x$-ray of the patient shown in figure 1

the bone remodelation in the area of alveolar bone. These data represent the evidence of suppression in bone remodelling and it is in accordance to hypothesis, that BP are lowering the remodelation in $\operatorname{BRONJ}(9,10)$. Resisting mucosa dehiscence are raising questions about the effect of BP to soft tissues. Because epitelisation is the most important step in surgery wound healing, there are hypotheses that soft tissues of mouth may play important role in development of BRONJ. One of key problems of this hypothesis is, whether the oral mucosa is exposed in vivo to sufficient levels of BP to harm physiologic processes. Although that this hypothesis is interesting and it's worthy of further study, it is more likely that the key point of BRONJ initiation is the bone tissue (8).

Table 1 BRONJ staging (2 - modified by author).

\begin{tabular}{|l|l|}
\hline \multicolumn{2}{|c|}{ BRONJ staging } \\
\hline At risk category & $\begin{array}{l}\text { No apparent necrotic bone in patients who have been treated with either oral or } \\
\text { intravenous bisphosphonates }\end{array}$ \\
\hline Stage 0 & $\begin{array}{l}\text { No clinical evidence of necrotic bone, but nonspecific clinical findings and symp- } \\
\text { toms }\end{array}$ \\
\hline Stage 1 & Exposed and necrotic bone in asymptomatic patients without evidence of infection \\
\hline Stage 2 & $\begin{array}{l}\text { Exposed and necrotic bone associated with infection as evidnced by pain and eryt- } \\
\text { hema in the region of exposed bone with or without purulent drainage }\end{array}$ \\
\hline Stage 3 & $\begin{array}{l}\text { Exposed and necrotic bone in patients with pain, infection and one or more of the } \\
\text { following: exposed and necrotic bone extending beyond the region of alveolar bone, } \\
\text { resulting in pathologic fracture, extraoral fistula, oral antral/oral nasal communi- } \\
\text { cation, or osteolysis extending to the inferior border of the mandible or the sinus } \\
\text { floor }\end{array}$ \\
\hline
\end{tabular}


Treatment of this disease varies from case to case. Recommendation of the AAOMS divides this disease into stages $0-3$ (Table 1). Treatment should be considered according to stage of the disease. But also general conditions of the patient should be reviewed, so the modifications of the treatment depend not only on local changes.

\section{MATERIAL AND METHODS}

We reviewed patients with BRONJ treated in University Hospital in Martin between the years 2006 and 2012. All of these patients underwent surgical therapy in Department of Stomatology and Maxillofacial Surgery. The study group consisted of 79 patients. There were 31 men and 48 women in the group. Average age was 65 years; age range was $41-91$ years. Most of the patients were administered for treatment by the dentist (95\%), only a few were sent by oncologists. All of the men used BF because oncological disease (prostate cancer, multiple myeloma), most women too (breast cancer, multiple myeloma - 87\%) and only 6 women (13\%) took BF therapy because of osteoporosis. Most common was this complication in patients that used zolendronic acid (91\%), followed by other aminated $\mathrm{BF}$ - pamidronate, alendronate (8\%). Only 1 patient used clodronate - non aminated BF. All of the patients were examined, other factors, like acute inflammation were found in 4 patients. All of the patients were examined also by x-ray in orthopantomographic projection. Minor dental surgery as an evoking factor was found in most of the patients -70 . Only 2 cases were caused by denture irritation and 7 cases occurred spontaneously next to teeth with periodontitis. The mandible was affected in $81 \%$, maxilla $17 \%$ and two patients had affected both alveolar bones.

The presence of one or more BRONJ risk factors as defined by the American Society of Oral and Maxillofacial Surgery (2) was identified in 32 patients (40\%). Most prevalent was smoking (13.1\%), followed by poor oral hygiene (9.1\%) the intake of cytostatic drugs $(5.6 \%)$ and intake of steroids (5.6\%).

Background for the surgery was made, if the general condition of the patient was satisfactory and if the patient approved the procedure after full informing. Drug holiday was always consulted with physician who prescribed the BF. When it was possible, it was preferred at least two months break before surgery and about $3-5$ months after the surgery, what depend on quality of the healing process. When the pus exudation from the stricken area was found, the therapy was started with antibiotics (ATB), mostly amoxicilinclavulanate and the antibiotic treatment was adjusted after examining the microbes' sensitiveness. Patients were divided into groups, depending on stages (Table 1), that were determined by AAOMS in the position paper (5). Therapy is afterwards chosen by stage of the disease.

Minor surgery - sequesterectomy was performed in local anesthesia in localized defects, that responded well to the antibiotic therapy and there was none or minimal dehiscence of the mucosa $(<1 \mathrm{~cm})$, but recurring purulence without ATB and sequester findings of the $\mathrm{x}^{-}$ ray. After application of regional anesthesia the mucosal flap was uncovered and the sequesters were removed, if some tooth was in the area, it was extracted. The bone was smoothened, granulation tissue removed and a liable suture was made.

When the dehiscence was larger than the sequestered bone, it was preferred to perform a horizontal resection of the alveolar bone. In general anesthesia was removed the inflamed mucosa surrounding the dehiscence, the bone was cut off with the high-speed drill and smoothed. Teeth were extracted only from the operated area, or sometimes when the trauma by the opposite tooth was threatening it was removed too. Like by the sequesterectomy the removed bones were administered for histopathological examination. Suture was made with non-absorbing stitching material.

Late stages, determined by the clinical examination (extra oral fistula, pathologic fracture) or the x-ray (necrosis reaching the opposite site of the bone) was indicated for segmental 
resection, when we combined intra oral surgery with extra oral excision of the fistula. By CT or MRI examination the borders of the resection were found and no reconstruction was made, after removing the segment. Only occasionally in frontal area, it was necessary to reconstruct the defect with plate osteosynthesis and suture the muscles of the tongue to it for prevention of the tongue sinking. Also in these cases was made the histopathological examination for differentiation of the metastatic process.

All the delivered tissue excisions were processed by common formalin-paraffin laboratory procedure and were dyed with hematoxylin-eosin, but also with special dying procedures for Actinomyces and mold organisms detection. Some bone fragments were decaltificated before cutting into $6 \mathrm{~m}$ thin sections.

All patients were in the time of the surgery covered by ATB prophylaxis. Treatment by antibiotics continued also 2-3 weeks after the surgery. The nasogastric tube was used for feeding after major operations. Sutures were removed on 10 th -14 th postoperative day and the follow up was 2 years. All complications, recurrences, reoperations and also the time of the treatment were recorded and evaluated.

\section{RESULTS}

As a primary surgery technique was most commonly chosen sequesterectomy. It was performed in 47 patients. Primary healed were 27 operational wounds, without any progression in the follow-up period. 20 patients had complications, which in 18 cases continued into progression to next stage and more radical reoperation - horizontal resection in 16 and segment resection in 2 patients. Average time of healing in patients undergoing sequesterectomy was 3.25 months. Altogether were made 48 horizontal resections, out of which 32 were as a primary operating technique. This procedure lead to complete healing without major complications in 31 cases, 17 patients had complications and segment resection as a next step was performed in 6 cases. Average healing time in group of horizontal resection was 4.75 months. Together were made 8 segment resections of a mandible, with average healing in 6.75 months, 1 patient needed reoperation and one affection progressed and is nowadays in a process of therapy, without sure effect (Table 2).

Table 2 Used surgery techniques overview

\begin{tabular}{|l|c|c|c|c|c|c|}
\hline & $\begin{array}{c}\text { Surgeries } \\
\text { done }\end{array}$ & $\begin{array}{c}\text { As a primary } \\
\text { treatment }\end{array}$ & $\begin{array}{c}\text { Healed per } \\
\text { primam }\end{array}$ & Complications & Progressions & $\begin{array}{c}\text { Time of } \\
\text { management }\end{array}$ \\
\hline Sequesterectomy & 47 & 47 & 27 & 20 & 18 & 3.25 \\
\hline Horizontal resection & 48 & 32 & 31 & 17 & 6 & 4.75 \\
\hline Segment resection & 8 & 0 & 6 & 1 & 1 & 6.75 \\
\hline Total & 103 & & 64 & & & \\
\hline
\end{tabular}

Intraoperative complications were not recognized. One of the patients died during the follow up, but not as a result of the osteonecrosis. The postoperative complications with their percentage are shown in (Table 3). 
Table 3 Complications

\begin{tabular}{|c|c|c|c|c|}
\hline Complication & & $\%$ & $\begin{array}{l}\text { Healed after } \\
\text { intervention }\end{array}$ & $\begin{array}{c}\text { Success of complication } \\
\text { treatment }\end{array}$ \\
\hline Minor dehiscence of the wound & 9 & $11.4 \%$ & 7 & $78 \%$ \\
\hline Oronasal communication & 1 & $1.3 \%$ & 1 & $100 \%$ \\
\hline Oroantral communication & 3 & $3.8 \%$ & 2 & $67 \%$ \\
\hline Progression & 25 & $31.6 \%$ & 24 & $96 \%$ \\
\hline Total in patients & 38 & $48.1 \%$ & 34 & $92 \%$ \\
\hline Total in all surgeries made & & $36.9 \%$ & & \\
\hline
\end{tabular}

Rate of success in complications treatment was satisfactory. Two patients with minor dehiscence of the mucosa refused reoperation and during the follow up period were not found any progressions or purulent secernation. One patient with resulting oronasal communication was treated successfully with palatal obturator. One patient with oroantral communication is planned for reoperation. A patient with segment resection in the frontal area of the mandible is now in therapy process after removing the osteosynthetic plate, which was causing progression. A small dehiscence was resutured, but the effect of the treatment is still uncertain.

Histological image of the necrosis bone tissue was in the cases of BRONJ similar to the necrosis after the radiotherapy. There weren't found any changes that could be helpful in determination of the necrosis pathogenesis. There were fragments of the necrotic lamellar bone with significant reversion lines, without evidence of accordingly stainable cellular bone components (osteocyts, osteoblasts or osteoclasts). Also were necrotic the fragments of the fibrotized bone marrow, in which there was occasionally possible to be found the low cellulized, non-specific granular tissue. Frequent part of the examined tissue were variably rich and large colonies of the "Actinomyces-like" organisms, which were characteristic by dark purple circumference and lighter, eosinophilic centre of the tangled microorganisms. These microorganisms were positive to Periodic acid-Schiff (PAS) staining, and also to the Grocott-Gomori methenamin-silver staining (GGMS). Evidence of the malignant epithelium cells wasn't found, in spite of using epithelium antibodies, in any of the examined tissues.

\section{DISCUSSION}

Bisphosphonates are daily used drugs and a number of BF prescriptions is rising. In year 2010 were in the USA prescribed 27 million prescriptions for oral BF (11). In Europe are more likely indicated in oncological patients, but there is also rising popularity of BF for osteoporosis treatment. It is becoming common that general practitioner prescribes $\mathrm{BF}$ for osteoporosis. It's not a good concept, because the patient has to be well examined before prescribing, including 24 hours $\mathrm{Ca}^{2+}$ excretion in urine, calciferol level in serum and other possible risk factors that are joined with BRONJ.

Our present experience shows, that patients are very often under-informed about possible complications in oral cavity by using bisphosphonates. Prescribing specialists are not forcing patient to radical removal of all risky and well restoration of all remaining teeth before using $\mathrm{BF}(12,13,14)$. Also dentists are just slowly accustoming the fact, that before the tooth extraction they should be asking also for usage of BF (15). These steps would be for sure a big leap in prevention of this disease. 
In diagnostic process was in our study most commonly used conventional x-ray examination. It displays the thickness of lamina dura, signs of osteolysis, diffusion sclerosis and poor or none healing of the extraction wounds. Correlation between radiological and clinical findings showed, that in patients with mild BRONJ are characteristic sclerotic changes in alveolar bone with thickening of lamina dura (16). As we had commonly found little differences between the x-ray and intraoperative findings, it was not significant regarding to the treatment effect.

Almost all patient in the study discontinued BF for the time of the BRONJ treatment. Although it is known, that bisphosphonates are bind to the bone tissue for years, the AAOMS has still drug holiday in the position paper. Previous treatment schemes also used discontinuation. But it's recommended to let the prescribing physician to decide, whether the condition of the primary disease allows the discontinuation. Multiple studies support the drug holiday, because it's shown that BF affect also soft tissues by inhibiting oral epithelial cell migration into the socket after extraction $(17,18,19)$. Discontinuation of the $\mathrm{BF}$ provides no short-term benefit, but if the primary disease conditions allow the long-term discontinuation, it can be beneficial in stabilization of the wounds after surgery, reduction of progression into new areas and weakening of the BRONJ symptoms. Modification in the $\mathrm{BF}$ treatment can be done only after the agreement of the patient and his attending physician (oncologist, hematologist or rheumatologist). In the study was no patient with dangerous worsening of the disease because of the drug discontinuation.

Unclear role in the pathogenesis plays the infection of the site. Often is in the biopsy found the colonization by "actinomyces - like" organisms, what correlates with other studies (7, 20). It is still unclear whether the infection plays crucial or secondary role in the BRONJ. But the antimicrobial therapy is very important in the time of BRONJ treatment. Most of the species found are sensitive to penicillin group. Chinolones, metronidazol and doxycyclin were successfully used in patients allergic to penicillin. Microbiologically should be proven also the Actinomyces colonization with treatment adjustment made if necessary.

The healing time is long, it is counted in months. Longest was in the group of segment resection, what can be caused also by the fact, that none of the patients was indicated for a segment resection in early examination, all of the resections were made by progression of the disease.

The surgical treatment of BRONJ is led by a guideline in AAOMS position paper. More often are chosen surgical procedures that are less invasive as a first step; it is also suggested not to remove periosteum from the surrounding bone, so the eyesight control of the surrounding bone is limited. This can be a reason of relatively high number of complications. But it is pleasing that most of these complications were treated well.

\section{CONCLUSION}

Osteonecrosis of the jaw caused by bisphosphonates is still a challenging problem. Unclear pathophysiology, together with lots of other risk factors conductive to BRONJ refuses unique treatment. There is request for a national or better world register of BRONJ patients, with all their characteristics, treatments results and complications. This could help in understanding the BRONJ (21). AAOMS position paper still remains unequaled in treatment recommendations, but it has to be adjusted individually for each patient. Although the results of the BRONJ therapy are satisfactory, the long time treatment is needed, the quality of life is often worsened even after the treatment, so the prevention is the only way of incidence reduction. 


\section{REFERENCES}

1. Stanton DC, Balasanian E. Outcome of surgical managment of Bisfosfonate-Related Osteonecrosis of the Jaws: Review of 33 Surgical Cases. J Oral Maxillofac Surg 2009 (67): 943-950.

2. Ruggiero SL, Dodson TB, Assael LA, Landesberg B, Marx RE, Mehrota B. American Association of Oral and Maxillofacial Surgeons Position Paper on Bisfosfonate-Related Osteonacrosis of the Jaws-2009 Update. J Oral Maxillofac Surg 2009, Suppl 1 (67): 2-12.

3. Marx RE. Pamidronate (Aredia) and Zolendronate (Zometa) induced avascular necrosis of the jaws: A growing epidemic. J Oral Maxillofac Surg 2003 (61): 1115.

4. Ruggiero SL, Mehrotra B, Rosenberg TJ, Engroff SL. Osteonecrosis of the jaws associated with the use of bisphosphonates: a review of 63 cases. J Oral Maxillofac Surg 2004 (62): 527-34.

5. Advisory Task Force on Bisfosfonate-Related Osteonacrosis of the Jaws. American Association of Oral and Maxillofacial Surgeons Position Paper on Bisfosfonate-Related Osteonacrosis of the Jaws. J Oral Maxillofac Surg 2007 (65): 369.

6. Abu-Id MH, Warnke PH, Gottschalk J, Springer I, Wiltfang J, Acil Y, Russo PAJ, Kreutsch T. "Bis-phossy jaws" - High and low risk factors for bisphosphonate-induced osteonecrosis of the jaw, J Oral Maxillofac Surg 2008 (36):95-103.

7. Tubiana-Hulin M, et al. Physiopathology and management of osteonecrosis of the jaws related to bisphosphonate therapy for malignant bone lesions. A French expert panel analysis. Crit Rev Oncol/Hematol (2008), doi: 10.1016/j.critrevonc.2008.10.009

8. Allen MR, Burr DB. The Pathogenesis of Bisfosfonate-Related Osteonecrosis of the Jaw: So many Hypotheses, So Few Data, J Oral Maxillofac Surg 2009, Suppl 1 (67): 61-70.

9. Sonis ST, Watkins BA, Lyng GD, Lerman MA, Anderson KC. Bony changes in the jaws of rats treated with zolendronic acid and dexamethazone before dental extractions mimic bisphosphonate-realted osteonecrosis in cancer patients. Oral Oncology 2009 (45):164-172.

10. Allen MR, Burr DB. Mandible matrix necrosis in beagle dogs after 3 years of daily oral bisphosphonate treatment. J Oral Maxillofac Surg 2008 (66): 987.

11. Assael LA. Oral Bisfosfonates as a Ceuse of Bisphosphonate-Related Osteonecrosis of the Jaws: Clinical Findings, Assessment of risks, and Preventive Strategies. J Oral Maxillofac Surg 2009, Suppl 1 (67): 35-43.

12. Capsoni F, Longhi M, Weinstein R. Bisphophonate-associated necrosis of the jaw $>$ the rheumathologist's role. Arthritis Res Ther 2006 (8):219.

13. Woo SB, Hellstein JW, Kalmar JR. Systematic Review: Bisphosphonates and Osteonecrosis of the Jaws. Ann Intern Med 2006 (144):753-61.

14. Woolhorton E. Patients retrieving intravenous bisphosphonates should avoid invasive dental procedures. CMAJ $172: 1684,2005$

15. Otto S, et al., Osteoporosis and bisphosphonates-related osteonecrosis of the jaw: Not just a sporadic..., Journal of Cranio-Maxillo-Facial Surgery 2010, doi:10.1016/j.jcms.2010.05.009

16. Arce K, Assael LA, Weissman JL, Markiewitz MR. Imaging Findings in Bisfosfonate-Related Osteonecrosis of Jaws. J Oral Maxillofac Surg 2009, Suppl 1 (67): 75-84.

17. Landesberg R, Cozin M, Cremers S, Woo V,Kousteni S, Sinha S, Garrett-Sinha L, Raghavan S. Inhibition of oral mucosal cell wound healing by bisphosphonates. J Oral Maxillofac Surg 2008 (66):839-47.

18. Scheper MA, Badros A, Chaisuparat R, Cullen KJ, Meiller TF. Effect of zolendronic acid on oral fibroblasts and epithelial cells: a potential mechanism of bisphosphonate-associated osteonecrosis. British Journal of Haematology, 2008, doi: 10.1111/j.1365-2141.2008.07504.x

19. Kobayashi Y, Hiraga T, Ueda A, Wang L, Matsumoto-Nakano M, Hata K, Yatani H, Yoneda T. Yolendronic acid delays wound healing of the tooth extraction socket, inhibits oral epithelial cell migration and promotes proliferation and adhesion to hydroxyapatite of oral bacteria, withou causing osteonecrosis, in mice. J Bone Miner Metab 2010 (28): 165-175.

20. Hansen T, Kunkel M, Springer E, Walter C, Weber A, Siegel E, Kirkpatrick CJ. Actinomycosis of the jaws - histopathological study of 45 patients shows involvement in bisphophonate-associated osteonecrosis and infected osteoradionecrosis. Virchows Arch. 451:1009-1017, 2007

21. Gliklich R, Wilson J. Epidemiology of Bisphosphonate-Related Osteonecrosis of the Jaws: The Utility of a National Registry. J Oral Maxillofac Surg 2009 Suppl 1 (67): 71-74.

Received: July, 30, 2013

Accepted: September, 6, 2013 